\title{
Razzle Dazzle
}

\section{En camoufleret avantgarde}

Det er ofte blevet fremført, at avantgardebegrebet er tæt forbundet med realpolitiske interventioner, krige og terror (Slome og Simon 2009; Virilio 2003). De historiske avantgarder - som f.eks. futurisme, dadaisme, surrealisme og konstruktivisme - er hermed også ofte blevet fortolket som en reaktion på krig og totalitarisme (Adamson 2007, 182). I vores tid bliver der stadig ofte etableret forbindelser mellem krig, terrorisme og kunst. Samtidskunsten med dens nye politiske billedtyper og aktionsformer kan således heller ikke tænkes uafhængigt af hverken revolutionens eller krigens sfære, som det f.eks. afspejles i de mangefacetterede aktioner, som i de seneste år er blevet udført af f.eks. den russiske feministiske punk- og protestgruppe Pussy Riot, de anonyme medlemmer af den amerikanske feministiske kunstner- og aktionsgruppe Guerilla Girls, de omfattende opstande, som blev iværksat af Occupy-bevægelsen og dens fraktioner, Reclaim the streets, den Hamborgbaserede bz-og teaterorganisation Rote Flora eller de franske libertære medlemmer af Den Usynlige Komité m.fl. Fælles for dem er, at de alle er forsøgt elimineret eller undergravet af statsmagtsapparatet, idet de er blevet betragtet som korrektiver til og reorganiseringer af den herskende magts doktriner, eller i visse tilfælde ligefrem som militante organiseringer og oprørsceller. Men da de alle også er arnested for nye kunstneriske udtryksformer, er det samtidig nærliggende at antage, at begreber som krig, politisk opstand og kunst faktisk er krydsforbundne på tværs af tidslige skel og geografiske rum (Stubblefield 2015, 3.). På samme måde har mange af de kunstneriske bevægelser såsom surrealisterne, dadaisterne, konstruktivisterne og de Internationale Situationister arbejdet politisk revolterende samtidig med, at de har formået at skabe en lang række kunstværker, som sidenhen er blevet indlemmet i kunstinstitutionerne. Lidt polemisk hævder jeg i forlængelse heraf, at det ikke kun er avantgardernes obstruktive, anarkistiske og libertære kampmetaforik, der bør definere dem, men samtidig den måde, hvorpå avantgardisternes erfaringer blev implementeret i den vestlige verdens kontrarevolutionære og kapitalistiske statsmagtsapparat, herunder dens militær. Omdrejningspunktet for denne artikel 
er hermed ikke først og fremmest at vise, hvordan krigen repræsenteres i de singulære kunstværker, men derimod at illustrere, hvordan erfaringerne fra de historiske avantgarder lod sig implementere direkte i krigsindustriens arbejde med udviklingen af camouflage, hvilket først og fremmest afspejles med Razzle Dazzle-maleriets opkomst i begyndelsen af det 20.århundrede. Med artiklen vil jeg vise, hvordan camouflageteknikken Razzle Dazzle - som blev påført krigs- og handelsskibene i begyndelsen af 1900-tallet - korresponderede med mange af tidens forskellige afarter af avantgardekunst, samt at Razzle Dazzle-teknikken ikke kan tænkes uafhængigt af den viden, som opstod inden for zoologien og gestaltpsykologien. Med andre ord vil artiklen med udgangspunkt i camouflageteknikken Razzle Dazzle undersøge, på hvilke måder og i hvilket omfang den militære sektor og avantgarderne øvede gensidig indflydelse på hinanden i tiden omkring 1 . verdenskrig.

\section{Razzle Dazzle - camouflagens kunst}

I 1917 opfandt den i dag forholdsvis ukendte britiske marinemaler Norman Wilkinson teknikken Razzle Dazzle-camouflage, som er karakteriseret ved brugen af rene farver og geometriske former, om end den i praksis ofte udmøntede sig i sort-hvide bemalinger. Uanset ændringerne fra idé til praksis er det opsigtsvækkende, at det var en traditionel konservativ marinemaler, som tilsyneladende trak erfaringerne fra avantgarde-kunsten direkte ind i camouflageindustrien (Holm 2003, 42). 1917 var også året, hvor USA lancerede sit American Camouflage Corps. I lyset heraf er det ikke underligt, at Wilkinson året efter tog på ophold i USA for at introducere amerikanerne for sin nye camouflageteknik. I disse år meldte en del unge kunstnere sig også frivilligt til militærtjeneste i håbet om at få en karriere som camouflage-designere. Der herskede en nærmest desperat stemning for at arbejde med de nye visuelle billedsimulationer og fortifikationsformer, og Wilkinsons "reklamefremstød" for Razzle Dazzle-teknikken virkede også efter hensigten: Amerikanerne endte med at forsyne 36 destroyere med den (Holm 2003, 44 f.).

Med termen camouflage forstås ofte det at skjule noget ved at lade et objekt sammensmelte med det miljø, som det er en del af. Denne camouflageform kaldes typisk for baggrundsmatchning. Problemet med baggrundsmatchning er dog dels, at det konkrete miljø, som et objekt skal skjules i, er i konstant forandring, og dels at objektet, som skal skjules, ikke må være i fart (Scott-Samuel et al. 2011, 1). Allerede i 1897 kunne kunstneren Abbott H. Thayer konstatere, at grunden til, at mange dyr, i særdeleshed fugle, er hvide på brystet og mørke på ryggen skyldes, at de benytter sig af kontrastskyggen som camouflageteknik, om end den kun virker, fordi de samtidig er i stand til at standse enhver form for bevægelse (Behrens 2014). Ud fra Thayers tidlige observationer er det indlysende, at baggrundsmatchning kan være en dårlig camouflagestrategi for fartøjer i drift, og det særlige ved Razzle Dazzle var også netop, at disse bemalinger skulle få angrebsmålene, i form af skibe, til at lyse op på havet fremfor at skjules i det omgivende miljø, da deres konstante bevægelse alligevel umuliggjorde sidstnævnte. Hvor man tidligere uden succes havde fors $\varnothing \mathrm{gt}$ at skjule flåden ved at påføre fartøjerne forskellige nuancer, som skulle ligne havets, herunder den berømte marineblå eller Battleship Grey, dér udviklede Wilkinson 
Razzle Dazzle-teknikken ud fra en på mange måder oppositionel camouflageteori. For som kunsthistoriker og ph.d.-stipendiat ved CBS Ditte Vilstrup Holm har påpeget, var Razzle Dazzle:

6 såre enkel. Man forsøgte ikke at skjule skibene, men derimod at forvirre fjenden, de tyske ubåde, med hensyn til skibenes retning, størrelse og fart. Skarpe lin[j]er på skroget gjorde det sværere at bestemme hvor skibets stævn befandt sig - og dermed hvilken retning skibet bevægede sig i. Påmalede falske bovbølger signalerede en falsk fart - og øgede igen muligheden for fejlbedømmelse fra ubådens side. (Holm 2003, 40)

Det, at skibene ikke længere blev forsøgt tilpasset omgivelserne i tiden omkring 1. verdenskrig, udløste en totalforvirring hos fjenden. På det niveau kan camouflageteknikken opfattes som en praktisk applikation af de bemærkninger, som Picasso sendte i et brev til sin ven forfatteren og kunstneren Jean Cocteau: "If they want to make an army invisible at a distance they have only to dress their men as harlequins" (Picasso efter Forbes 2009, 105). I den sammenhæng minder Razzle Dazzle også om den måde, som visse dyr, såsom kamæleoner og giftfrøer, forsøger at afværge deres fjender på. Med deres stærke farver og via optiske effekter indtager disse dyr en særlig position, idet de primært benytter sig af en strategi, hvor det handler om at signalere fare ved at blive set. En anden, men dog relateret strategi, kender vi fra zebraer (Hogan et al. 2016, 2); store rovdyr, herunder løver, har vanskeligt ved at

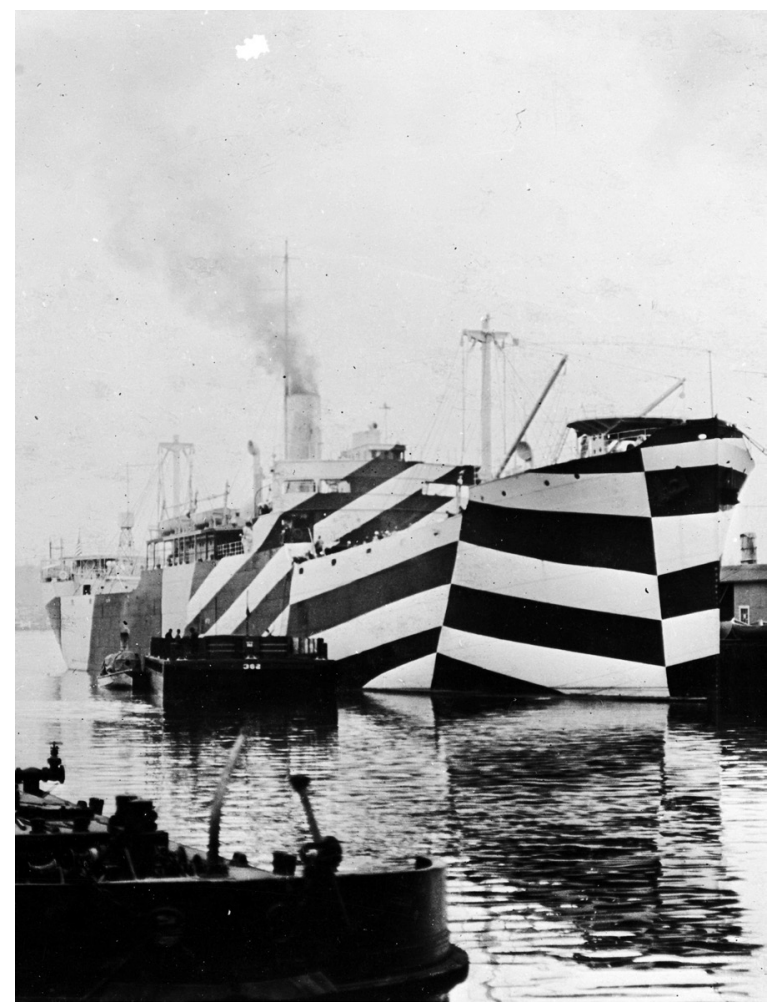

(c) U.S. National Archives, Bureau of Ships Collection 1918. 
angribe zebraer, idet den enkelte zebra, takket være de sort-hvide striber, er i stand til at forvirre fjenden. Det skyldes, at så længe en zebra befinder sig i flokken, flyder den visuelt sammen med massen. Camouflage handler således ikke kun om at beskytte sig selv via baggrundsmatchning-strategier, men også om en funktionsbestemt kombinatorisk udvikling og udnyttelse af forskellige optiske bedrag og chokeffekter. Ligesom avantgarderne handler Razzle Dazzle i al sin enkelhed derfor først og fremmest om at skabe forvirring og chok.

Wilkinsons arbejde med at bemale krigsskibe på nye måder udgjorde et del-element i en større oprustning på camouflagefronten. Ud over camouflagekorpsenes arbejde med at designe observationsposter, der bl.a. skulle ligne de træer, som posterne blev placeret imellem, havde man også eksperimenteret med at male lange vejstrækninger på lærreder, som efterfølgende blev udspændt så højt hævet over jorden, at tropperne kunne bevæge sig frit under dem. Derudover skabte camouflagekompagnierne dukker i menneskestørrelse, som lignede rigtige tropper, ligesom man udviklede de mønstrede uniformer, som i dag kan betragtes som camouflagens signatur par excellence. Det italienske ord for camouflage camuffare, som betyder at narre, er hermed meget dækkende for de camouflagestrategier, som blev udviklet i tiden omkring 1. verdenskrig. Med introduktionen af Razzle Dazzle handlede det imidlertid ikke længere om at forsøge at skjule krigsskibene på traditionel vis, men derimod om at forvirre fjenden ved at skabe virkningsfulde chokeffekter, idet de, forsynet med kraftige bemalinger, skulle lyse op og dermed forvirre den. Det var imidlertid ikke kun krigsskibene, men også handels- og togtskibe, som blev forsynet med Razzle Dazzle, og det anslås, at ca. 4000 britiske handelsskibe blev malet i denne særlige teknik. Razzle Dazzle kan hermed også opfattes som en defensiv strategi, idet den skulle hjælpe transport- og civile skibe med ikke at blive torpederet af de ubådsflåder, som også først fik en krigsstrategisk betydning under 1. verdenskrig. Hermed var kunstnerne i camouflagetjeneste heller ikke kun nationalistisk stemte, men derimod også pacifistisk orienterede.

Desuagtet de muligvis mere pacifistiske argumenter for introduktionen af avantgardeinspireret camouflage, er forbindelserne mellem avantgarde og krigsførelse under 1. verdenskrig mange og signifikante. Det er således sigende, at Wilkinson, der egentlig havde været en traditionel marinemaler før krigen, tog en avantgardistisk strategi i brug, da han satte sig for at camouflere flåden, og at han med denne nye camouflageteknik formåede at skabe en geometrisk ren og formålsrationaliseret kunst, der var helt i tråd med f.eks. de russiske konstruktivisters politiske og kunstneriske arbejde med at skabe funktionsbestemte værker. Ud over Wilkinson kan nævnes den i udgangspunktet radikale engelske avantgardekunstner Edward Wadsworth, der ofte arbejdede med geometriske abstraktioner i tæt dialog med de russiske konstruktivisters programmer. Wadsworth blev også ansat i den engelske flådes Dazzle-kompagni, hvor han fungerede som kunstnerisk vejleder for bemalingen af 2000 skibe (Deer 2009, 45). Wadsworth havde allerede omkring 1913 arbejdet tæt sammen med bl.a. forfatteren Ezra Pound og Wyndham Lewis om lanceringen af vorticismen, som var en britisk avantgarderetning, der med udgangspunkt i navnlig futurismen og kubismen fik en meget kort levetid i begyndelsen af det 20. århundrede. Vortiticisterne samledes omkring udstillingsstedet og diskus- 
sionsklubben Rebel Art Centre, som Wyndham Lewis havde fået etableret i London i 1914. Rebel Art Centre fungerede således som et naturligt samlingssted for de mest revolutionære forfattere og billedkunstnere i tiden, heriblandt Wadsworth. Men Wadsworth fik også gengivet flere af sine sort-hvide geometriske værker i det avantgardistiske tidsskrift Blast, som kun udkom med 2 numre, og i et meget begrænset oplag i 1914 og 1915. I det første nummer af Blast kunne medstifterne bl.a. præsentere læserne for det første vorticistiske manifest, ligesom tidsskriftet generelt kan ses som en eksplicit hyldest til fart, flux og maskin- og industrisamfundets destruktive kraft og potens. Det første nummer bestod af en ensfarvet lyserød forside, hvilket står i stærk kontrast til det andet nummer, som var forsynet med en forside, der illustrerede en futuristisk-inspireret krigsscene ledsaget af teksten War Number. Det andet nummer af Blast udkom den 15. juli 1915, og det indeholdt foruden gengivelserne af Wadsworths værker også tekster af Ezra Pround og T.S. Eliot. Kunstneren Henri Gaudier-Brzeska, der døde samme år, bidrog desuden med en artikel med titlen "Vortex (written from the Trenches)".

Blast var kendetegnet ved at være i dialog med flere af de radikale kontinentaleuropæiske avantgardeformationer ikke mindst de italienske futurister, som tidsskriftet layoutmæssigt også lå i klar forlængelse af, men også en konstruktivistisk kunstner som Kandinsky satte tydeligvis sit præg på tidsskriftet, der i øvrigt også

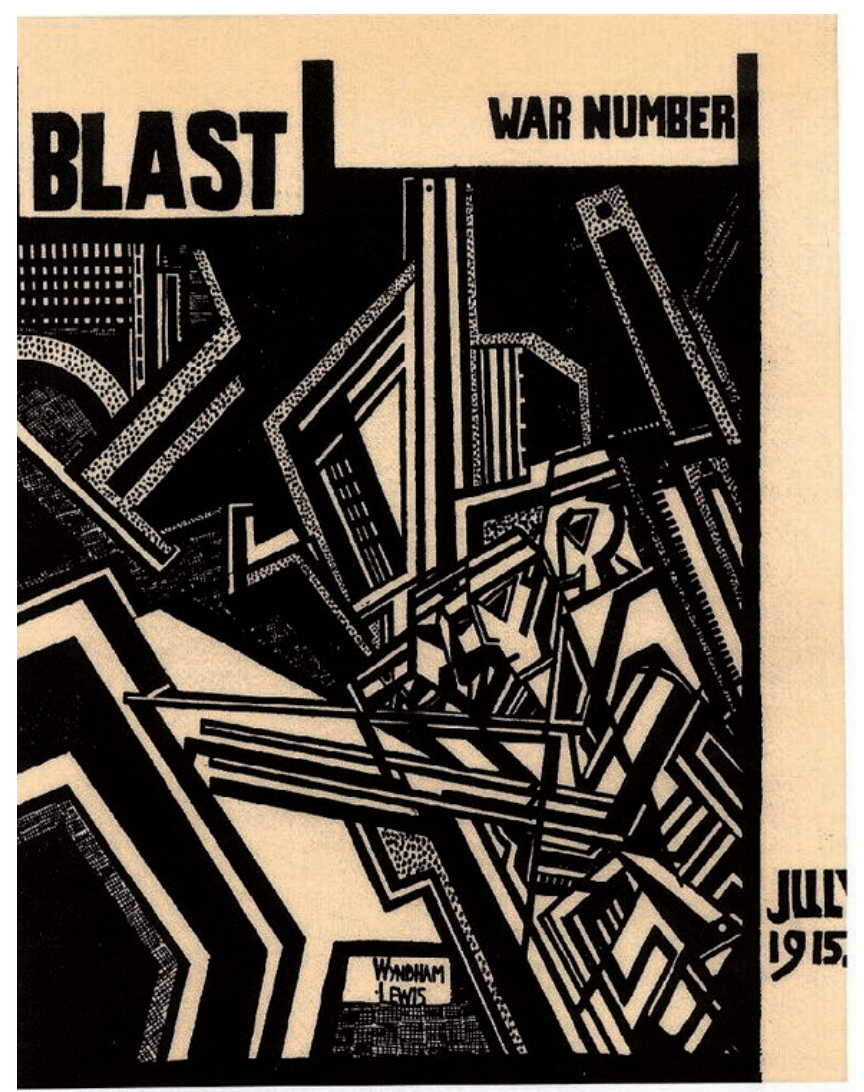

Cover af Blast (1915). (C) Wyndham Lewis et al. 1915

Parallellerne mellem Razzle Dazzle-camouflage og vorticistisk kunst er tydelige 
rummede en beskrivelse af hans kunst. At Blast var i dialog med flere af tidens avantgarder, ikke mindst via den hyppige brug af krigsmetaforik, fremgår desuden tydeligt af flere af tekstindslagene. De kaotiske og sammensatte elementer ved Blast har gjort det vanskeligt at klassificere tidsskriftet, der også indeholder satiriske indslag, i lighed med dadaisternes produktioner, i kombination med dets mere destruktive futuristiske karakter. Dette fremgår i særdeleshed af det første nummer, hvori Wyndham Lewis f.eks. påpegede, at: "Killing somebody must be the greatest pleasure in existence. Either like killing yourself without being interfered with by the instinct of self-preservation - or exterminating the instinct of self-preservation itself!" (Lewis 1914, 133); “Cézanne was an imbecile, as Rosseau was a 'Policeman', Nature's defense for Cézanne against the deadly intelligence of his country was to make him a sort of idiot" (ibid. 137) og: "But just as the old form of egoism is no longer fit for such conditions as now prevail, so the isolated human figure of most ancient Art is an anachronism" (Lewis 1914, 141). De nære forbindelser, der kan trækkes mellem avantgardekunsten og krigsindustrien i tiden omkring 1. verdenskrig, er også blevet fremhævet af den amerikanske litteraturprofessor Patrick Deer. I bogen Culture of Camouflage understreger Deer, at militæret friktionsfrit kunne opsluge og dermed kapitalisere de resultater, som avantgarderne fremkom med (Deer 2009, 44). Derudover viser Deer, hvordan f.eks. den tyske ekspressionistiske maler Franz Marc, som var medstifter af Blaue Reiter, blev involveret direkte i krigsindustrien som camouflagemaler:

64 Across No Man's Land, the German expressionist painter Franz Marc, a friend of Klee and Kandinsky, was seconded from the cavalry to paint nine huge tarpaulins 'to hide artillery emplacements from airborne spotters and photography'. Referring to them as 'Kandinskys' in letters to his wife, he painted them 'in roughly pointillist designs in the manner of bright natural camouflage.' (Deer 2009, 44)

Efterhånden blev der udviklet en hel industri for camouflagemaleri, hvilket som sagt afspejles ved, at der på Royal Academy of Fine Arts i London blev nedsat et Dazzle Department på initiativ af Wilkinson. Men det skal samtidig understreges, at camouflageteknikkens historie udgør et lige så spraglet mønster som dens egen visuelle fremtoning. Allerede i 1915 var det franske camouflagekorps Les Peintres de la Guerre au Camouflage blevet grundlagt på initiativ af den militærinteresserede kunstner Lucien-Victor Guirand de Scevola. Den britiske pendant til Les Peintres de la Guerre au Camouflage hed Special Works Park, og det blev oprettet i marts måned 1916 og husede bl.a. medlemmer af Artists' Rifles såsom skulptøren Leon Underwood, som var en tidligere elev af ophavsmanden til futurismen Filippo Marinetti (Deer 2009, 44). På Les Peintres de la Guerre au Camouflage trak man bl.a. veksler på kubister som Jacques Villon og Raoul Dufys erfaringer, og under 1. verdenskrig havde Picasso efter sigende også set en camoufleret kampvogn passere forbi ham på Boulevard Raspail i Paris, hvorefter han skulle have sagt, at der kører vores (Picassos og Georges Braques) kubisme (Deer 2009, 44; Forbes 2009, 104). I 1949 blev denne fortælling alment kendt takket være Braque, der i et interview fastslog, at han var meget glad for, at hæren i 1914 havde taget de kubistiske principper til sig (Forbes 2009, 104). 


\section{Perception, zoologi og avantgarde}

Avantgardens bidrag til camouflagekunsten opstod ikke i et vakuum, men udgjorde en del af en større udforskning af perception og gestaltning og af, hvordan man konstruerer visuelle imaginationer og optiske billedeffekter, som de delte med zoologer og psykologer. Under 2. verdenskrig blev zoologer således også ansat som camouflageeksperter i krigsindustrien, som det f.eks. afspejles i zoologen Hugh Cotts indgående arbejde med at skjule våben direkte i felten. Sommerfugle, i særdeleshed arten Kallima, fik stor indflydelse på udviklingen af camouflageteknikken, og det skyldes, at denne sommerfugleart er i stand til at mutere visuelt alt afhængig af de omgivelser, som den befinder sig i. Hermed dannede Kallima-sommerfuglen et grundlag for arbejdet med, hvordan man kunne skabe illusionistiske simulationsbilleder (Forbes 2009, 115 ff.). Det er således ikke underligt, at camouflageteknikken og teorien herom blev videreudviklet af bl.a. zoologen John Graham Kerr og den tidligere nævnte kunstner Abott H. Thayer, som i øvrigt også arbejdede tæt sammen i perioder (Forbes 2009, 85). Med Razzle Dazzles ambition om at sætte fjenden/ den andens perspektiviske blik ud af drift for en stund ved at besværliggøre reel afstandsbedømmelse af det objekt, som ønskes destrueret, markerer teknikken en bevægelse væk fra det traditionelle kartesianske centralperspektiviske blik. Samtidig indskriver Razzle Dazzle sig i en fænomenologisk tradition, hvor det handler om, hvordan kroppen er en aktiv del af det rum, som den befinder sig i. Denne pointe understreges også i psykoanalytikeren og strukturalisten Jacques Lacans analyse af mimicry. I sin teori om mimicry fokuserede Lacan på capellakrebsenes evne til at gøre sig til en plet for derved at forsvinde i den bryozoras biotop, som krebsen selv indgår i (Lacan 2004, 88). ${ }^{\mathrm{I}}$ Lacan trak af samme grund eksplicit forbindelse mellem mimicry og camouflage, som når han i seminar XI i 1964 koncist fremhævede, at:

64 Mimicrys effekt er camouflage i den egentligt tekniske betydning. Det drejer sig ikke om at bringe sig i overensstemmelse med baggrunden, men på en broget baggrund at gøre sig broget - præcis ligesom camouflageteknikken anvendes i menneskelige krigsoperationer. (Lacan 2004, 89)

Lacan kan endvidere via sin blikteori berige vores syn på den forsimplede ven-fjende dikotomi, eftersom betragteren og det betragtede, ifølge Lacan, altid indskriver sig som en plet i det samme overstrukturerende skopiske felt. At overvågningen udgør en af de vigtigste faktorer i krig vidner om, at krigen og blikket forstået som magt også altid er tæt knyttet til hinanden, selvom den, der overvåger også altid selv er overvåget. Det er måske ikke tilfældigt, at Lacan udviklede sine blikanalyser på en fisketur med vennen og fiskeren Petit-Jean. Her så Lacan en sardindåse, der lå i solflimmeret på havet, og herved indså han, at den i virkeligheden betragtede ham på samme måde, som han så den (Lacan 2004, 85). Lacans teori om blikket kan ikke adskilles fra hans berømte opdelinger i de tre ordner, Det imaginære, Det symbolske og Det reelle. Det imaginære henviser til det imaginære spejlstadie. Her kan afstanden mellem beskuer og objekt komme til udtryk på to måder, enten ved, siger Lacan, at barnet genkender sit eget spejlbillede, eller ved at moderen stirrer tilbage på barnet. Anerkendelsen af den anden opstår således ved, at barnet i første omgang 
identificerer sig med spejlbilledet og dermed tilpasser sig det imaginære objekt. Det er i den sammenhæng nærliggende at opfatte spejlstadiet som tæt forbundet med baggrundsmatchning-camouflagen, hvor det handler om at tilpasse sig billedet i form af den baggrund, som objektet befinder sig på og dermed underkaste sig den andens blik. Omvendt er det også oplagt at opfatte Razzle-Dazzle som en særlig manifestation af den fænomenologiske viden, der handler om, at hvis det camouflerede skib kan betegnes som et objekt, der stirrer tilbage på sin fjendtlige betragter, så må den traditionelt entydige magtforskel mellem den, som angriber, og den, som camouflerer sig, samtidig forskydes og opfattes som ustabil. Med Razzle Dazzle er vi lidt forenklet på vej over i det, Lacan betegner som Den symbolske orden, som er kendetegnet ved barnets brud med spejlbilledet, her forstået som et dyadisk forhold mellem betragter og objekt (Lacan 1973, 49). For som Lacan bemærker, er det, når barnet genkender sig selv som spejlbillede, at det konstitueres som subjekt i verden, idet barnet samtidig adskiller sig fra spejlbilledet (moderen) via noget tredje (Lacan 1973, 51). Lacans fokus på dobbeltgængeren som markør for denne bevægelse fra imaginær til symbolsk orden kan på det niveau sammenlignes med den måde, hvorpå Razzle Dazzle-mønstrene altid gør objektet u-fikserbart. Razzle Dazzle-objektet ser med andre ord ud til at være et andet sted end der, hvor det faktisk er.

Razzle Dazzles fokus på at udvikle nye teknikker for, hvordan man får et objekt til at fremstå som optisk og rumligt u-afgrænseligt, deler den med avantgardebevægelser såsom kubisme, konstruktivisme, dadaisme og ikke mindst efterkrigstidens neoavantgarder, herunder opart-kunstnernes bestræbelser. Fælles for disse på mange måder ellers forskellige kunstarter og stile er, at de alle forsøger at negere renæssancens konstruerede perspektiviske tredimensionelle rum til fordel for en anden og mere dynamisk gestaltpsykologisk og kropsorienteret fænomenologisk rumopfattelse.

Det er f.eks. oplagt, at der både kan udpeges formelle og gestaltteoretiske lighedspunkter mellem den måde, hvorpå op-art og kinetiske kunstnere som Victor Vasarely og Bridget Riley og Razzle Dazzle-malerne arbejdede, hvilket også Forbes har konstateret (Forbes 2009, 91;100). Selv en ellers konservativ marinemaler som Wilkinson kunne konstatere, at fikserbilleder viser os noget om, hvordan en genstand eller et objekt reelt aldrig kan indtage en statisk forrangs-position i rummet (Kristensen 2015, 165). Denne gestaltpsykologiske viden formåede Wilkinson at integrere som en aktiv del af den nye krigsførelse (Forbes 2009, 90). Wilkinson sammenlignede effekten af Razzle Dazzle med den situation, at man i et stillestående tog perceptuelt registrerer bevægelse, udelukkende fordi toget ved siden af bevæger sig (Forbes 2009, 91). Det skal her indskydes, at oplevelsen af fart imidlertid afhænger af mange forskellige faktorer, f.eks. vil større objekter altid se ud som om, de bevæger sig langsommere end mindre, og forskellige former og teksturer kan også have indvirkning på, hvordan farten perciperes (Scott-Samuel et al. 2011, 3). Det er i den sammenhæng bemærkelsesværdigt, at Razzle Dazzle-malerne benyttede sig af rette linjer og streger, idet geometriske former i særdeleshed kan ophæve figur-grund-dikotomien i synsoplevelsen - noget som den franske kubist og senere konkrete kunstner Auguste Herbin også fremhævede i sin farveteori fra 1949 (Herbin 1949). 


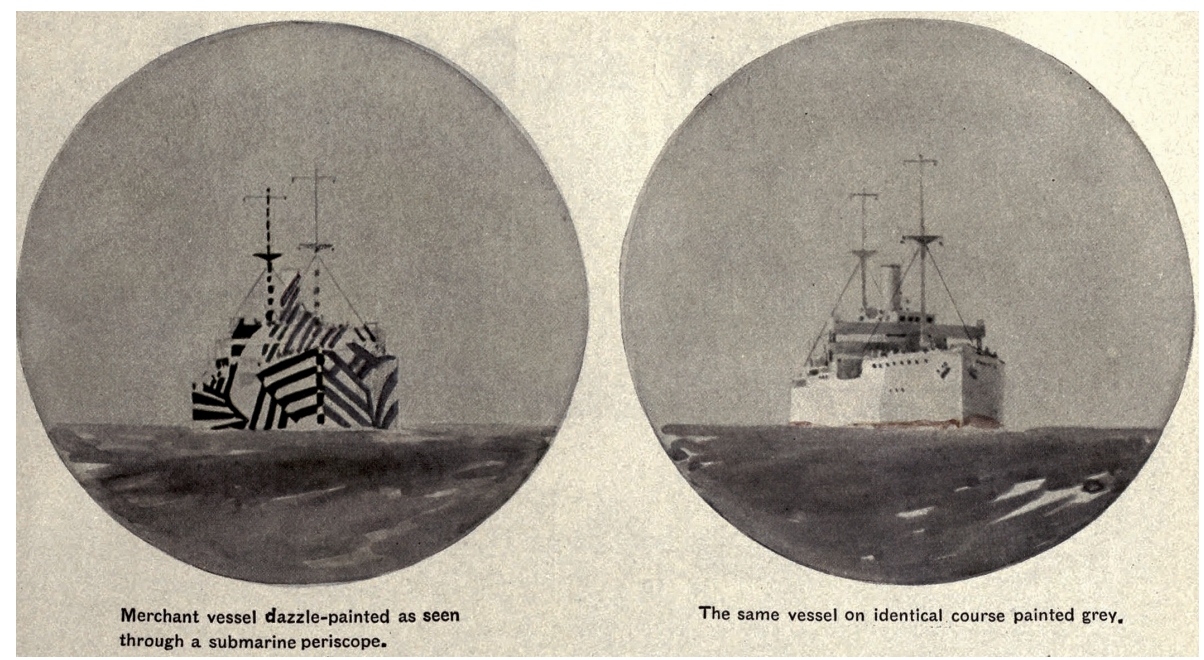

EB 1922 @ Wikipedia. En kunstners fremstilling af Razzle Dazzle-camouflage set gennem et ubådsperiskop

Den danske gestaltpsykolog Edgar Rubin, som havde udviklet den berømte teori om kippefænomenet (bedre kendt som vaseteorien), tog bl.a. afsæt i Bauhauslederen og konstruktivisten Kandinskys kunst. I det banebrydende pionerværk om de synsoplevede figurer fra 1915 havde Rubin allerede gjort den vigtige iagttagelse, at:

6 Det gælder for Stregen som for Konturen, at den skifter Karakter, alt efter om den opleves som hørende til den ene eller den anden Flades figur. Naar man ved en Smule komplicerede reciprokke Mønstre, frembragt ved Hjælp af Streger, skifter mellem at opleve det ene eller det andet af Stregerne betingede Feltsystem som Figur, kan man undertiden bemærke, at Stregfiguren i den Grad skifter Karakter, at det er meget vanskeligt, efter at den oplevede Fladefigur har skiftet, at identificere et bestemt Stregstykke, man havde bidt Mærke i, da det andet Feltsystem oplevedes som Figur. (Rubin 1915, 163)

Som biologerne Benedict Hogan, Innes C. Cuthill og Nicholas E. Scott-Samuel for nylig har påpeget, rummer rette linjer bemalet parallelt med angrebsmålet faktisk mange camouflagemæssige forcer, om end spørgsmålet om, hvor hurtigt objektet kan vendes, og om det optræder singulært eller i grupper, også må tillægges større betydning for Dazzle-maleriets reelle effekt end hidtil antaget (Hogan et al. 2016, 1). Ud fra nutidige undersøgelser af computerbaserede spil har det endvidere vist sig, at højkontrast-mønstrede angrebsmål blev ramt sjældnere end dem, som var udført efter baggrundmatchning-camouflagens principper (ibid. 2).

\section{Om avantgardebegrebet og dets historiske relation til krig}

Begrebet avantgarde, som etymologisk betyder fortrop, blev oprindeligt anvendt som et militærbegreb. Den militærhistoriske betydning af begrebet har imidlertid efterfølgende også haft en betydelig afsmitningseffekt på vores fællesforståelse af avantgarden som kulturbegreb. Det betyder, at avantgarden som kulturbegreb fortsat sættes i forbindelse med en særlig destruktiv variant af kunsten som angrebs- 
strategi. Den subversive kritik, som mobiliseres blandt avantgarderne, kan hermed opfattes som direkte udslagsgivende i destruktive handlinger, idet kampen mod kapitalismen konstant må finde sted via nye og dermed ikke autoriserede kanaler. Den hollandske avantgardeteoretiker Hubert van den Berg har også fremhævet, hvordan avantgardebegrebet som kulturfænomen stadig konnoteres til dets oprindelige militære betydning som en "partisanlignende" fortropsorganisering, selvom avantgarden uintenderet blev indlemmet i de statslige systemer, som avantgarderne hermed kan siges kun at stå kortvarigt og partikulært i opposition til:

46 .

'Avantgardens' fremskudte position; dens placering i frontlinjen, forud for hovedstyrkerne, og dét at den opererer relativt isoleret som for at bekendtgøre noget større, der er i vente; dens operationer på fjendtligt territorium; dens rekognoscerende funktion - disse og andre aspekter relateres derpå i den kulturelle sfære til fremkomsten af nye bevægelser med kurs mod en ny kunst og nye kulturelle praksisformer, der har til opgave at udforske disse nye måder og tackle den modstand, de undervejs møder fra eksisterende traditionelle gamle styrker, før det evt. lykkes dem at etablere sig som en ny kulturel eller politisk orden.(van den Berg 2005, 24)

Med andre ord bliver avantgarderne fortsat associeret med udadrettede angrebsstrategier frem for med mere komplekse struktureringer, selvom statsinstitutionerne, herunder krigsindustrien, tilsyneladende ubesværet fik assimileret avantgardekunstnerne til deres kooperative krigsprogrammer. Det har medført, at avantgarderne tilsyneladende er blevet kapitaliserede, legitimerede og dermed aftappede for enhver form for eksteriørt kritisk potentiale. Razzle Dazzle er et konkret eksempel på, hvordan de ellers revolterende avantgardister blev skjult, "camouflerede" og tilpasset til den samfunds- og normbevarende statsligst organiserede krigsindustri, som de på mange måder burde forventes at stå i opposition til.

Det 20. århundrede er blandt historikere hyppigt blevet beskrevet som de store katastrofers tid med de store verdenskrige som historiens matrice. Den britiske historiker Eric Hobsbawm har i den forbindelse karakteriseret perioden 1914 til 1991 som ekstremernes tid (Hobsbawm 1996). Den turbulente og totalitaristiske periode i europæisk historie, som i særdeleshed prægede den første halvdel af det 20. århundrede, er som nævnt også avantgardekunstens blomstringstid. Avantgarde-begrebet og krig er på den måde komplekse, sammenkittede begreber, og de er således fortsat uadskillelige, som det også pointeres af den franske filosof Paul Virilio:

64 What can you say, meanwhile, about the likes of Richard Hülsenbeck, one of the founding fathers of dada, who told a Berlin audience in 1918, at a conference on the new trends in art, 'we were for the war. Dada today is still for war. Life should hurt. There is not enough cruelty!' The rest is history. Twenty years later the "Theatre of Cruelty" would not be the one defined by Antonin Artaud but by Kafka, that prophet of doom of the metamorphosis engineered by the camps, the smashing to smitherness of humanism. The slogan of the First Futurist Manifesto of 1909 - 'War is the world's only hygiene' - led directly, though thirty years later this time, to the shower block of Auschwitz-Birkenau. (Virilio 2003, 29) Når fænomener som krig og avantgardekunst er så tæt forbundne, som Virilio stadig 
opfatter dem som, så skyldes det ikke kun de historiske avantgardisters paroler og agitationsformer og deres bidrag til camouflageindsatsen, men dertil også mange af kunstnernes aktive krigsdeltagelse som front- og skyttegravssoldater. Et af de klassiske eksempler er forfatteren Ernst Jüngers senere beretninger fra sine fire år som skyttegravssoldat, eller de fremtrædende italienske futurister som Marinetti, Achille Funi og Antonio Sant'Elia, der på baggrund af deres aktive deltagelse i 1 . verdenskrig skabte en tilsvarende subversiv, kaotisk og anarkistisk kunst. Ligesom den norske kunstner Per Krogh, der ligeledes havde deltaget under 1. verdenskrig, favoriserede futuristerne krigens eliminationspotentialer, idet de ønskede enhver borgerlig og traditionsforvaltende samfundsnorm destrueret. Den italienske kunstner Umberto Boccioni afbrændte f.eks. det østrigske flag, hvilket medførte, at han blev fængslet, mens hans futuristiske ven og støjmusikkens fader Luigio Russolo blev integreret i den såkaldte lombardiske cykelhær (Holm 2003, 42).

Ifølge futuristerne skulle krigen opfattes som en form for hygiejne, ligesom den fart, teknologi og energi, som krig altid repræsenterer, samtidig spejlede de nationalistiske futuristers fascistoide fascinationer og venerationer. De italienske futurister ønskede historiske monumenter såsom museer, teatre, templer og kirker nedrevet til fordel for opbygningen af en ny tidssvarende by etableret på krigens grundprincipper om fart og flux:

6 We see ourselves as the destructive nitric acid that it would be well to throw over all political parties, as they are in a state of putrefaction. In our Futurist Manifesto, published in Le Figaro, in Paris, we extolled Patriotism, War - the sole cleanser of the World - the destructive acts of the anarchists, and the beautiful ideas worth dying for, gloriously opposed to the ugly ideas of which we live. Certainly, these accustomed to thinking of patriotism and war as being totally opposed to anarchism, which caused so many lives to erupt, in the struggle for greater freedom. (Marinetti 2006, 61)

I det lys har futuristernes idé om destruktionen som avantgardistisk strategi paralleller til terroristernes totaldestruktion af World Trade Center, og det er således heller ikke underligt, at den tomme plads for det "faldne monument" i form af tvillingetårnene er blevet tildelt prædikatet Ground Zero (det skal understreges, at jeg her eksplicit tager afsæt i den italienske Milano-baserede del af futurismen og ikke f.eks. af de russiske kubu-futurister eller ego-futurister, der ikke besad den samme volds-parathed som Marinetti og hans følgere). Som kunsthistorikeren Ernest Ialongo har påpeget, er futurismen også kendetegnet af modsætninger og kontinuerligt sammenbrudsramte tilstande, og det skal derfor også understreges, at Marinetti på den ene side må betegnes som en ekstrem anarkistisk individualist, på den anden side som en nationalistisk stemt utopist, hvis primære ønske bestod i at samle hele folket (Ialongo 2015, 5). Jeg mener, at den omskiftelige betydning, som krigen har haft i en kunstnerisk optik, er væsentlig for at forstå, hvorfor nogle af de kunstnere, som sidenhen skulle tage afstand fra krigen, tidligere havde idealiseret den og endda taget fysisk del i den, som det f.eks. var tilfældet med kunstnere som Otto Dix og Georg Grosz. Den måde, hvorpå man tidligere har generaliseret og analogiseret f.eks. dadaisterne og ekspressionisterne som udelukkende udtryk 
for pacifistiske bevægelser, i modsætning til futurisme som voldelig og krigsstemt, virker stærkt forsimplet ud fra denne korte skitsering af deres fælles engagement i krigsindustrien og Dazzle-kompagnierne. I lighed med futuristerne dyrkede Dix i begyndelsen af sin karriere det kraftfulde ved krigen, intetheden og det kaotiske, og efter sigende drog han også i krig med Friedrich Nietzsches samlede værker som sin eneste personlige ejendel. Som mange af de øvrige dadaister, såsom billedkunstnerne John Heartfield, Hugo Ball og Marcel Duchamp, udviklede Grosz og Dix efterhånden en stærk aversion mod krig, hvorfor de også sidenhen blev særdeles aktive medlemmer af den kunstretning, som gik under betegnelsen Neue Sachlichkeit. Disse detaljer har til formål at vise, at det med udgangspunkt i avantgardekunstnernes fællesarbejde i camouflagekorpsene er muligt at tegne et mere nuanceret billede af, hvordan kunstnerne på tværs af de enkelte avantgardestrømninger, og dermed uanset deres eventuelle indbyrdes kunstneriske og teoretiske uoverensstemmelser, tilsyneladende alle kunne indlemmes i en krig og rustningsindustri, som grundlæggende var etableret i kampen for såvel nationalstatsprincipperne som de borgerlige værdier.

\section{Konklusion}

Med fokus på Razzle Dazzle-malernes brug af optiske effekter har denne artikel fors $\varnothing \mathrm{gt}$ at tegne et mere nuanceret billede af avantgarderne, herunder hvordan der kan trækkes nye partikulære forbindelser mellem avantgarderne og begreber som fortifikation og camouflage (Holm 2003, 40). Dette billede bidrager også med kontekst til den traditionelle opfattelse af avantgarderne - futurisme, konstruktivisme, dadaisme, surrealisme m.m. - som analoge til de mange antikapitalistiske og revolutionære modorganiseringer, der indfandt sig i det politiske liv i begyndelsen af det tumultariske 20. århundrede, og viser at de, uanset deres utopiske projekter, alle gradvist blev amputerede som subversive korrektiver til de herskende samfundsordner og normer. Og uanset deres ellers forskellige politiske mål og midler er det også fælles for de historiske avantgarder, at de alle gradvist er blevet kanoniserede, hvorved de friktionsfrit er blevet assimileret til middelklassens æstetiske smag (Bürger 1974, 84ff.). Der findes således ikke længere en egentlig avantgarde, for som kunsthistorikeren og samfundskritikeren Mikkel Bolt har konstateret:

4 Få kunstnere forsøger, som f.eks. surrealisterne gjorde det i 1920'erne og 1930'erne, at alliere sig med revolutionære bevægelser eller politiske partier. Den forbindelse mellem kunstnerisk eksperiment og politisk engagement, som var en nødvendighed for surrealisterne, er tilsyneladende ikke længere mulig. (Bolt 2013, 17)

Denne dystopiske tese blev allerede forvarslet i 1980 af kunstkritikeren og journalisten Robert Hughes, som i tv-programmet og den efterfølgende bog The Shock of The New (Det chokerende nye) fremlagde et nærmest tilsvarende synspunkt: 
16 Mellem 1880 og 1930 udspilledes i Europa og Amerika et af de største eksperimenter i verdenshistorien. Efter 1940 blev det forædlet, udviklet her og dér og endte med at være en slags entropisk, institutionel parodi på sit gamle jeg. Mange mennesker mener, at modernist-laboratoriet nu står tomt. Det er i mindre grad blevet skueplads for betydelige eksperimenter og mere til en slags museumssal for en tidsperiode, et historisk rum, vi kan gå ind i, kigge på, men ikke længere være en del af (Hughes 1981, 9).

Hvad Hughes altså gør opmærksom på er, at de store revolutioners tid, som alle udspillede sig før udbruddet af 2. verdenskrig, rummede en både chokerende og revolterende impuls samt en utopisk tro på, at det var muligt at opbygge et nyt klasseløst samfund, hvori kunsten og kulturen stadig spillede en aktiv rolle. Kunsten skulle således inkorporeres og installeres i det hverdagslige og politiske liv, som den selv skulle sammensmelte med og dermed deltage i. I den optik er det nærliggende at opfatte Razzle Dazzle som et overgangsfænomen, der markerer avantgardernes første implementering i krigsindustrien som en spæd indvarsling af deres egen undergang og forfald.

\section{Noter}

I Mimicrybegrebet blev oprindeligt lanceret i 1961 af den engelske zoolog Henry Walter Bates. Med den teori, som i dag betegnes som Bates' mimicry, blev det endelig påvist, at der er morfologiske ligheder mellem giftige og ikke giftige insekter.

\section{Litteratur}

Adamson, Walter L. (2007): Embattled Avant-Gardes - Modernism's Resistance to Commodity Culture in Europe, Los Angeles: University of California Press.

Andersen, Svend (2005): “Krig og bekendelse - Kan en luthersk kirke mene noget om Irakkrigen?", Baudrillard, Jean (2003): Terrorismens ånd, København: Tiderne Skifter.

Baudrillard, Jean (2004): Amerika, København: Informations Forlag.

Behrens, R. Roy (2014): "Abbott H. Thayer's vanishing Ducks Survelliance, Art and Camouflage”, Mascontext.http://www.mascontext.com/issues/22-surveillance-summer-14/abbott-h-thayers-vanishing-ducks-surveillance-art-and-camouflage/ (tilgået 20. september 2018).

Berg, van den Hubert (2005): “Kortlægning af det nyes gamle spor - Bidrag til en historisk topografi over det 20. århundredes avantgarde(r) i europæisk kultur”, Tania Ørum et al. (red.): En tradition af opbrud-Avantgardernes tradition og politik, Hellerup: Spring, s. 19-44.

Bolt, Mikkel (2013): Avantgardens selvmord, Aarhus: Antipyrine.

Bürger, Peter (1974): Theorie der Avantgarde, Frankfurt am Main: Suhrkamp Verlag.

Deer, Patrick (2009): Culture in Camouflage - War, Empire, and Modern British Literature, Oxford: Oxford University Press.

Forbes, Peter (2009): Dazzled and Deceived - Mimicry and Camouflage, New Haven: Yale University Press.

Herbin, Auguste (1949): L'art non-figuratif non-objectif, Paris: Edition Lydia Conti.

Hirst, Paul (2003): Krig og magt i det 21. århundrede, København: Hans Reitzels Forlag. 
Hobsbawm, Eric (1996): Age of Extremes - The Short Twentieth Century 1914-1991, London: Abacus. Hogan, Benedict G. et. al. (2016): "Dazzle camouflage, target tracking, and the confusion effect", Behavioral Ecology 27, Oxford: Oxford Journals, s. 1-9. https://www-ncbi-nlm-nhi-gov-. ep.fjernadgang.kb.dk/pmc/articles/PMC5027625/ (tilgået 20. september 2018).

Holm, Bo Kristian (red.): Krig - Dens legitimitet i religion og politik, Frederiksberg: Anis, s. 77-93.

Holm, Ditte Vilstrup (2003): “Avantgarde-camouflage under første verdenskrig - Dazzle Painting”, Kulturo 17, s. 40-48.

Hughes, Robert (1981): Det chokerende nye - Kunsten og forandringens århundrede, København: Samlerens Forlag.

Ialongo, Ernest (2015): Filippo Tomasoi Marinetti: The Artist and his Politics, Madison: Fairleigh Dickinson University Press.

Kristensen, Jens Tang (2015): Når linjer trækkes op, skabes der afstand - En ny socialkunsthistorisk analyse af Linien IIs placering og status $i$ den danske kunsthistorie, belyst ud fra en unders $\varnothing$ gelse af gruppens forhold til avantgarderne som kunstnerisk strategi og politisk intervention, København: Ph.d.afhandling Det Humanistiske Fakultet, Københavns Universitet.

Lacan, Jacques (1973): Det ubevidste sprog - Psykoanalytiske skrifter, København: Rhodos.

Lacan, Jacques (2004): Psykoanalysens fire Grundbegreber - Seminar XI, København: Forlaget Politisk Revy.

Lewis, Wyndham (1914): "Vorteces and Notes", Blast - Review of the great English Vortex 1, London: The Bodley Head, s. 129-147.

Marinetti, F.T. (2006): “The Necessity and Beauty of Violence”, Günter Berghaus (red.): F.T. Marinetti Critical Writings, New York: Farrar Straus Giroux.

Mirzoeff, Nicholas (2005): Watching Babylon - The War in Iraq and Global Visual Culture, New York: Routledge.

Mitchell, W.J.T (2005): What Do Pictures Want - The Lives and Loves of Images, London: The University of Chicago Press.

Rubin, Edgar (1915): Synsoplevede figurer - Studier i psykologisk analyse, København: Gyldendals Boghandel, Nordisk Forlag.

Scott-Samuel et al. (2011): "Dazzle Camouflage Affects Speed Perception", Plos One 6, s. 1-7. https://www-ncbi-nlm-nhi-gov-.ep.fjernadgang.kb.dk/pmc/articles/PMC3105982/ (tilgået 20. september 2018).

Slome, Manon og Joshua Simon (2009): "Introduction”, Slome, Manon og Joshua Simon (red.): The Aesthetics of Terror, Milano: Edizioni Charta, s. 7-8.

Sontag, Susan (1985): Fotografi - Essays om billede og virkelighed, København: Fremad.

Stubblefield, Thomas (2015): 9/11 and the Visual Culture of Disaster, Bloomington: Indiana University Press.

Virilio, Paul (2003): Fear \& Art, London: Continuum. 